\title{
EDUKASI TEHNIK ASEPTIK SEDIAAN STERIL BAGI TENAGA KESEHATAN DI FASILITAS PELAYANAN KESEHATAN KABUPATEN SUMBA TIMUR NTT
}

\section{(ASEPTIC TECHNIQUE EDUCATION OF STERILITY FOR HEALTH WORKER AT HEALTH SERVICES FACILITIES OF SUMBA TIMUR NTT)}

\author{
Dewi Isadiartuti ${ }^{1}$, Sugiyartono ${ }^{2}$, Retno Sari3, Muh. Agus S. Rijal ${ }^{4}$, Dini \\ Retnowati $^{5}$ \\ 1,2,3,4,5 Departemen Farmasetika Fakultas Farmasi Universitas Airlangga \\ e-mail: dewi-i@ff.unair.ac.id
}

\begin{abstract}
The Government through Permenkes 72/2016 on Pharmaceutical Services Standards in Hospitals has provided guidance on the regulation of pharmaceutical service standards. Pharmaceutical services in the field of management of sterile preparations is one aspect that receives attention, because it will affect the quality of services provided to sufferers. East Sumba Regency is one of the East Nusa Tenggara provinces located in Eastern Indonesia. East Sumba Regency has a large enough population but health workers in health care facilities have limitations in getting the latest information. To answer this condition, training was held in collaboration with IAI PC East Sumba. The aim of the training is to increase the knowledge and skills of aseptic techniques for sterile preparations for health workers in health care facilities so that the quality of health services can be improved. The training was given in the form of lectures consisting of compatibility and stability material for parenteral preparations and dispensing materials for sterile preparations followed by the practice of aseptic techniques for sterile preparations. The training activity was attended by 49 participants consisting of pharmacists, nurses, midwives and pharmaceutical technical personnel who worked in hospitals, health services, health centers, clinics, and pharmacies in Sumba (East, Central and West). From the results of the evaluation of the activity, it was known that the participants gained knowledge and increased knowledge about the basic principles of aseptic techniques and there was an increase in the participants' understanding of the material provided.
\end{abstract}

Keywords: aseptic techniques, East Sumba, health service facilities, health workers

\begin{abstract}
abstrak
Pemerintah melalui Permenkes 72/2016 tentang Standar Pelayanan Kefarmasian di Rumah Sakit telah memberikan arahan mengenai pengaturan standar pelayanan kefarmasian. Pelayanan kefarmasian di bidang pengelolaan sediaan steril merupakan salah satu aspek yang mendapat perhatian, karena akan memengaruhi mutu pelayanan yang diberikan kepada penderita. Kabupaten Sumba Timur merupakan salah satu wilayah propinsi Nusa Tenggara Timur yang terletak di Indonesia Bagian Timur. Kabupaten Sumba Timur memiliki jumlah penduduk yang cukup besar akan tetapi tenaga kesehatan di fasilitas pelayanan kesehatan memiliki keterbatasan dalam mendapatkan informasi terbaru. Untuk menjawab kondisi tersebut diadakan pelatihan bekerjasama dengan IAI PC Sumba Timur. Tujuan pelatihan adalah untuk meningkatkan pengetahuan dan ketrampilan tehnik aseptik sediaan steril bagi tenaga kesehatan di fasilitas pelayanan kesehatan agar mutu pelayanan kesehatan dapat meningkat. Pelatihan diberikan dalam bentuk ceramah terdiri dari materi kompatibilitas dan stabilitas sediaan parenteral dan materi dispensing sediaan steril dilanjutkan dengan praktek tehnik aseptik sediaan steril.
\end{abstract}


Kegiatan pelatihan diikuti 49 peserta yang terdiri dari apoteker, perawat, bidan dan tenaga teknis kefarmasian yang bekerja di Rumah Sakit, Dinas Kesehatan, Puskesmas, Klinik, dan Apotek sedaratan Sumba (Timur, Tengah, dan Barat). Dari hasil evaluasi kegiatan diketahui peserta mendapatkan penyegaran ilmu dan peningkatan wawasan tentang prinsip dasar tehnik aseptik dan terdapat peningkatan pemahaman peserta terhadap materi yang diberikan.

Kata kunci: fasilitas pelayanan kesehatan, tehnik aseptik, tenaga kesehatan, , Sumba Timur

\section{PENDAHULUAN}

Undang-undang RI No. 36/2009 tentang Kesehatan menyebutkan bahwa kesehatan merupakan hak asasi manusia dan merupakan salah satu unsur kesejahteraan yang harus diwujudkan sesuai dengan cita-cita bangsa Indonesia [1]. Peningkatan derajat kesehatan masyarakat dapat diperoleh antara lain melalui pelayanan kefarmasian yang sesuai standar dan tersedianya sediaan farmasi yang aman, berkhasiat, bermanfaat, bermutu, dan terjangkau.

Kabupaten Sumba Timur merupakan salah satu kabupaten di Propinsi Nusa Tenggara Timur. Luas wilayah daratan Kabupaten Sumba Timur sebesar 7.000,5 $\mathrm{Km}^{2}$ terdiri dari beberapa pulau yaitu pulau besar (Pulau Sumba Timur) dan beberapa pulau kecil lainnya, yaitu Pulau Salura, Pulau Menggudu, Pulau Nusa, dan Pulau Kotak, sedangkan wilayah lautan seluas $8.373,53 \mathrm{Km}^{2}$ dengan panjang garis pantai $433,6 \mathrm{Km}$. Wilayah administrasi Kabupaten Sumba Timur meliputi 22 wilayah kecamatan yang terbagi dalam 140 Desa dan 16 Kelurahan. Jumlah penduduk Kabupaten Sumba Timur berdasarkan data pada Dinas Kependudukan dan Catatan Sipil Kabupaten Sumba Timur keadaan per 31 Desember 2014 mencapai 247.018 jiwa yang terdiri dari 126.982 jiwa penduduk laki-laki dan 120.036 jiwa penduduk perempuan dengan rata-rata tingkat kepadatan penduduk 35 jiwa per $\mathrm{Km}^{2}$. Berdasarkan hasil Susenas 2013 menunjukkan bahwa sebagian besar penduduk berusia 10 tahun ke atas tidak memiliki ijasah sebesar 47,41\% dan yang memiliki ijasah SD sebesar 25,03\%, memiliki ijasah SLTP 10,76 \%, ijasah SLTA 9,94\%, Diploma I/II 0,83 \%, Diploma III 0,43\%,dan Diploma IV, $\mathrm{SI} / \mathrm{S} 2 / \mathrm{S} 3$ sebesar $2,48 \%$.

Pembangunan kesehatan merupakan salah satu sektor yang mendapat perhatian serius dari Pemerintah Kabupaten Sumba Timur. Program pembangunan kesehatan diarahkan untuk meningkatkan kualitas kehidupan dan usia harapan hidup serta mempertinggi kesadaran masyarakat atas pentingnya hidup sehat. Penyediaan sarana kesehatan sebagai pemenuhan kebutuhan pokok dalam upaya meningkatkan taraf kesehatan masyarakat secara umum terus ditingkatkan dari tahun ke tahun. Dalam rangka menjamin ketersediaan pelayanan dasar kesehatan kepada masyarakat maka sarana minimal pelayanan kesehatan di wilayah Kabupaten Sumba Timur adalah Puskesmas, Puskesmas Pembantu, Polindes, serta Posyandu. Berdasarkan data Pemerintah Kabupaten Sumba Timur sampai dengan tahun 2013 terdapat sarana dan prasarana kesehatan sebagai berikut: 507 unit posyandu, 87 unit polindes, 20 puskesmas induk, 76 puskesmas pembantu, 1 Rumah Sakit Umum Daerah tipe C, dan 2 Rumah Sakit Swasta Tipe D. 
Pemerintah melalui Permenkes 72/2016 tentang Standar Pelayanan Kefarmasian di Rumah Sakit telah memberikan arahan yang jelas mengenai pengaturan standar pelayanan kefarmasian. Pelayanan kefarmasian meliputi pengelolaan sediaan farmasi dan pelayanan farmasi klinik. Peningkatan pengetahuan dan ketrampilan sumber daya manusia merupakan aspek yang berperan besar dalam menyelenggarakan pelayanan kefarmasian sesuai standar. Salah satu bentuk layanan kefarmasian yang diberikan pada masyarakat adalah pemberian dan penggunaan sediaan steril.

\section{METODE PENGABDIAN MASYARAKAT}

Fasilitas pelayanan kesehatan di Kabupaten Sumba Timur telah memiliki tenaga kesehatan yang memadai dalam menjalankan fungsinya untuk melayani masyarakat. Ketersediaan tenaga kesehatan ini merupakan modal bagi peningkatan layanan yang ada. Salah satu komponen pelayanan kesehatan adalah pelayanan kefarmasian yang meliputi pengelolaan sediaan steril dan pelayanan farmasi klinik.

Tim pengabdian masyarakat Fakultas Farmasi Universitas Airlangga telah memiliki pengalaman mengadakan pelatihan Tehnik Aseptik Dispensing Obat Steril Bagi Farmasis Rumah Sakit yang diikuti oleh Apoteker dari seluruh Indonesia sejak tahun 2008. Peningkatan pengetahuan dan ketrampilan tenaga kesehatan yang bertanggung jawab terhadap pelayanan kefarmasian di fasilitas pelayanan kesehatan Kabupaten Sumba Timur diharapkan menjawab permasalahan mitra. Peningkatan kompetensi tenaga kesehatan dilakukan melalui pelatihan. Dalam pelaksanaan program pelatihan ini dibutuhkan mitra yang dapat berfungsi sebagai komunikator, fasilitator dan administrator kegiatan. Organisasi Ikatan Apoteker Indonesia Pengurus Cabang Kabupaten Sumba Timur (IAI PC Sumba Timur) dipilih untuk menjembatani kegiatan yang dilakukan.

Fokus pelatihan yang diberikan oleh tim pengabdian masyarakat Fakultas Farmasi Universitas Airlangga adalah peningkatan pengetahuan dan ketrampilan peserta dalam manajemen tehnik aseptik dan pengelolaan sediaan steril sehingga dalam pelaksanaan dilakukan melalui pembekalan pengetahuan yang dibutuhkan, praktek terkait pencampuran sediaan steril, kunjungan ke fasilitas kesehatan dan diskusi mengenai permasalahan terkait dengan tehnik aseptik dan pengelolaan sediaan steril.

\section{HASIL DAN PEMBAHASAN}

Sosialisasi kegiatan yang dilakukan PC IAI Sumba Timur mendapat respon positif dari tenaga kesehatan sedaratan Sumba. Oleh karena itu kegiatan terbuka bagi tenaga kesehatan di fasilitas pelayanan kesehatan di luar Sumba Timur. Dari proses pendaftaran peserta, ada 52 peserta yang berminat untuk mengikuti pelatihan. saat kegiatan berlangsung 3 peserta berhalangan hadir.

Kegiatan pelatihan diawali dengan kunjungan tim pengabdian masyarakat Fakultas Farmasi Universitas Airlangga ke RSUD Umbu Rara Meha Waingapu Sumba Timur pada hari Jumat, 20 Juli 2018. RSUD Umbu Rara Meha Waingapu Sumba Timur merupakan Rumah Sakit tipe $\mathrm{C}$ yang telah terakreditasi Paripurna. Tim pengabdian 
masyarakat didampingi oleh Apoteker Penanggung Jawab Rawat Inap dan Farmasi Klinik melihat dan mendapatkan penjelasan mengenai pelayanan obat dan penyiapan peralatan dan pakaian steril di bagian CSSD.

Pelatihan dilaksanakan pada hari Sabtu, 21 Juli 2018 dimulai jam 08.00-12.30 WITA di aula Hotel Jimmi Waingapu meliputi kegiatan: Pembukaan (Sambutan dari Ketua Panitia, Ketua PC IAI Sumba Timur dan Kepala Dinas Kesehatan Kabupaten Sumba Timur), pengisian kuesioner dan pre-test; Ceramah terdiri dari 2 sesi, sesi 1 tentang Stabilitas dan Kompatibilitas Sediaan Parenteral dan sesi 2 tentang Tehnik Aseptik dan Dispensing Sediaan Steril; diskusi dan tanya jawab, post-test; Praktek Tehnik Aseptik dan Penutupan. Praktek tehnik aseptik yang diberikan meliputi (1) pengambilan larutan dalam ampul, (2) rekonstitusi injeksi kering dalam vial, (3) pencampuran injeki ke dalam infus dan (4) pelabelan IV admixture.

Dari hasil kuesioner diketahui kegiatan pelatihan diikuti oleh 49 tenaga kesehatan di fasilitas pelayanan kesehatan sedaratan Sumba (Sumba Timur, Tengah dan Barat) berusia antara 24 sampai 47 tahun, dengan $80 \%$ peserta merupakan tenaga muda (usia < 35 tahun). Peserta adalah apoteker, perawat, bidan dan tenaga teknis kefarmasian bekerja di rumah sakit, dinas kesehatan, klinik kesehatan, apotek, dan puskesmas. Sekitar $40 \%$ peserta belum mengetahui penerapan dan pemahaman Permenkes 72/2018 sedangkan $60 \%$ peserta telah mengetahuinya. Dari $60 \%$ peserta yang telah mengetahui sekitar $30 \%$ peserta telah menerapkan dispensing sediaan steril dan sisanya belum terlaksana di fasilitas pelayanan kesehatan tempat bekerja. Kendala yang dihadapi dalam penerapannya adalah fasilitas ruangan, belum tersedianya peralatan dan prosedur tehnik aseptik sediaan steril, dan sumber daya manusia yang belum terlatih.

Jenis pekerjaan tehnik aseptik yang telah dilakukan bagi fasilitas pelayanan kesehatan yang ada meliputi pelarutan sediaan steril dalam bentuk padat kering, pengenceran sediaan steril dan pencampuran sediaan steril dengan bentuk sediaan injeksi dalam wadah ampul, vial, infus dan injeksi antibiotika. Dari hasil kuesioner belum ada fasilitas pelayanan kesehatan yang menangani sediaan injeksi sitostatika. 


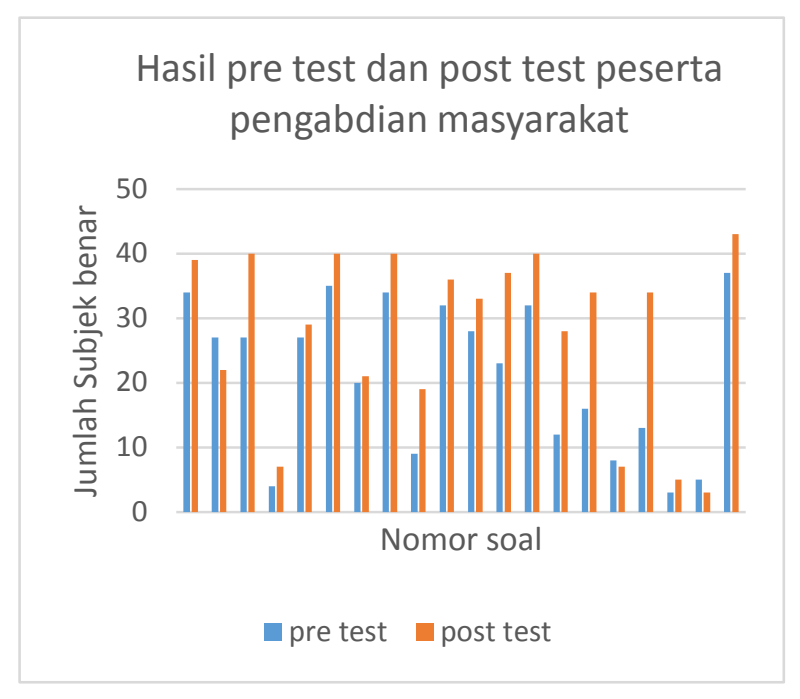

$1 \mathbf{a}$

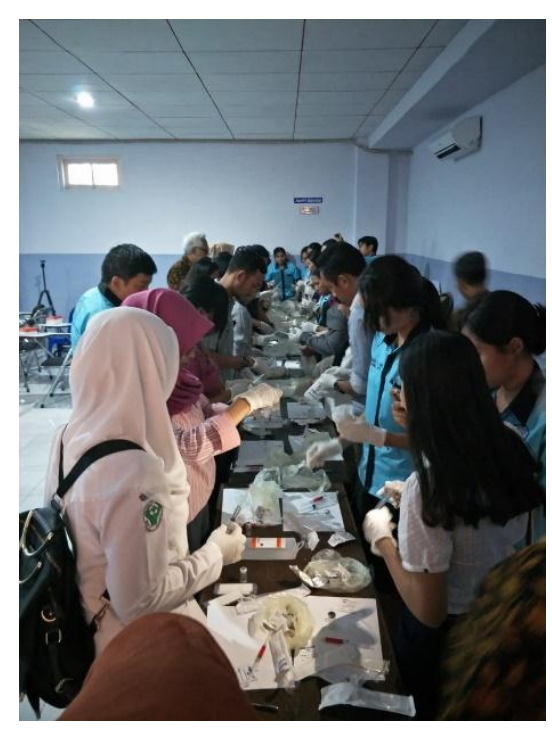

$1 \mathbf{b}$

Gambar 1.a. Histogram hasil pre/post test peserta pelatihan

1.b. Pelaksanaan kegiatan praktek tehnik aseptik

Dari hasil pre/post test (gambar 1.a) tentang pemahaman sediaan steril dan penerapan tehnik aseptik, diketahui terdapat peningkatan pemahaman terhadap materi yang disampaikan. Sebanyak 20 soal yang dikerjakan peserta, 17 soal menunjukkan peningkatan jawaban benar. Hal ini menunjukkan bahwa kegiatan pelatihan tehnik aseptik (gambar 1.b) yang diberikan dapat meningkatkan pemahaman tentang tehnik aseptik sediaan steril. Kegiatan pengabdian yang dilakukan juga mendapatkan perhatian dari media yang ada, dapat dilihat dari pemberitaan di 5 media di Sumba Timur .

\section{PENUTUP}

Dari kegiatan pengabdian masyarakat yang telah dilakukan dapat disimpulkan pelatihan tehnik aseptik sediaan steril dibutuhkan dalam menunjang pelayanan kesehatan masyarakat di daratan Sumba NTT. Agar penerapan pelayanan kefarmasian dapat optimal perlu didukung dengan pengadaan sarana dan prasarana yang ada di fasilitas pelayanan kesehatannya.

\section{Ucapan Terimakasih}

Ucapan terimakasih disampaikan kepada Fakultas Farmasi Universitas Airlangga yang telah mendukung kegiatan ini melalui dana RKAT tahun 2018, 


\section{DAFTAR PUTAKA}

Undang-undang Republik Indonesia No. 9/2009 tentang Kesehatan

Pedoman Dasar Dispensing Sediaan Steril, Direktorat Bina Farmasi Komunitas dan Klinik, Ditjen Kefarmasian dan Alat Kesehatan, Deparatemen Kesehatan RI, 2009.

Permenkes No. 72/2016 tentang Standar Pelayanan Kefarmasian Di Rumah Sakit

Blackburn J., 2009. Sterile Compounding and Preparations : A Kowledge

Based Program for Technician. Texas Tech University.

http://kupang.tribunnews.com.2018/07/21/fakultas-farmasi-unair-beri-pelatihan-teknikaseptic-sediaan-steril-kepada-iai-sumba-timur

http://kupang.tribunnews.com/2018/07/21/universitas-airlangga-lakukan-road-showpengenalan-fakultas-farmasi-di-waingapu

http://www.waingapu.com/2018/07/22/fakultas-farmasi-uanir-road-show-diwaingapudari-siswa-hingga-ke-studio-radio.html

http://maxfmwaingapu.com/2018/07/fakultas-farmasi-airlangga-lakukan-road-showdan-pengmas-di-sumba-timur

http://maxfmwaingapu.com/2018/07/fakultas-farmasi-universitas-airlangga-latih-paraapoteker-di-sumba 